\title{
DISTRIBUIÇÃO E ABUNDÂNCIA RELATIVA DE BAGRES MARINHOS (SILURIFORMES, ARIIDAE) NA BAÍA DE SEPETIBA, RIO DE JANEIRO
}

\author{
Márcia Cristina Costa de Azevedo ${ }^{1}$ \\ Francisco Gerson Araújo ${ }^{1}$ \\ Antônio Gomes da Cruz Filho ${ }^{2}$ \\ Alexandre Clístenes de Alcântara Santos ${ }^{3}$
}

\begin{abstract}
Distribution and RELATIVE ABUNDANCE OF THE MARINE CATFISH (SiluRIFormes, AriddaE) IN SePetiba BAy, Rio de Janeiro. Marine catfish (Ariidae) are abundant resources in otter trawl fisheries carried out at Sepetiba Bay, Rio de Janeiro (Lat. 22 $2^{\circ} 54,2^{\circ} 04^{\prime} \mathrm{S}$; Long. $43^{\circ} 34^{\prime}, 44^{\circ} 10^{\prime} \mathrm{W}$ ). Relative abundance and distribution were assessed, based in 158 fishing sampling at seven sites in the Bay, between July-1993 e June-1996. Five species were recorded in the following abundance rank order: Genidens genidens (Valenciennes, 1839), Cathorops spixii (Agassiz,1829), Sciadeichthys luniscutis (Valenciennes,1840), Netuma barba (Lacépède,1803), and Bagre marinus (Mitchill, 1814), the latter have been caught in only two samples. Marine catfish showed higher abundance in the inner Bay, with indication of spatial segregation. G. genidens was abundant in all sites of the inner Bay, C. spixii e N. barba, near to rivers mouths, and $S$. luniscutis, being widespread in all studied area. Sazonality was not evident, with few exceptions in some of the three annual cycles; G. genideris and S. luniscutis were more abundant in biomass in summer 1994/95 (G. genidens) and 1993/94 (S. luniscutis). G. genidens e N. barba show higher abundance (CPUE and biomass) between July-93 and June- 95 and $C$. spixii e S. luniscutis between July-95 and June-96. Total association index indicates a overall positive association among all species, with. higher Jaccard and Sorensen similarities coefficient for the pairs $C$. spixii/G. genidens, G. genidens/S. luniscutis, e C. spixii/S. luniscutis. Pearson linear correlation and Sperman rank indicate that $G$. genidens and $N$. barba are inversely correlated to $C$. spixii and S. luniscutis. Spatial segregation strategy may be explaining the coexistence of the marine catfish at Sepetiba Bay.

KEY WORDS. Siluriformes, Ariidae, fish ecology, marine catfish, Sepetiba Bay
\end{abstract}

A família Ariidae compreende os bagres marinhos e de água salobra, ocorrendo na zonas tropicais litorâneas, em águas pouco profundas e geralmente de fundo lodoso. Em geral procuram a desembocadura dos rios, estuários e regiões lagunares na época da desova (Figueiredo \& MENEZES 1978). São largamente

1) Laboratório de Ecologia de Peixes, Universidade Federal Rural do Rio de Janeiro. Antiga Rodovia Rio-São Paulo Km 47, 23851-970 Seropédica, Rio de Janeiro, Brasil.

2) Fundação Instituto de Pesca do Estado do Rio de Janeiro. Praça XV de Novembro, 2, $3^{\circ}$ andar. 20010-010 Rio de Janeiro, Brasil.

3) Departamento de Ciências Biológicas, Universidade Estadual de Feira de Santana. Campus Universitário, 44031-460 Feira de Santana-Bahia, Brasil. 
distribuídos ao longo da costa brasileira, apresentando grande importância econômica na região Sul do país com contribuições significativas nas pescarias artesanais (REIS 1986).

A Baía de Sepetiba apresenta ampla ligação com o mar, onde a família Ariidae destaca-se entre as mais abundantes, contribuindo com cerca de $28,5 \%$ do número e $28,8 \%$ do peso total capturado em arrastos de fundo experimentais (ARAÚJo et al. 1998). Cinco espécies de Ariidae foram registrados nesta Baía: Genidens genidens (Valenciennes, 1839), Netuma barba (Lacépède, 1803), Cathorops spixii (Agassiz, 1829), Sciadeichthys luniscutis (Valenciennes, 1840) e Bagre marinus (Mitchill, 1814) (ARAÚJo et al. 1998).

Informações sobre distribuição e abundância desta família foram obtidas em outras regiões do Brasil. CRAIG (1980) analisou a distribuição dos bagres marinhos na costa da região de Peruíbe, São Paulo, e MishiMA \& TANJI (1981) no complexo estuarino de Cananéia, São Paulo. Na Lagoa dos Patos, Rio Grande do Sul, ARAÚJO (1988) estudou distribuição espacial e temporal de três espécies da família Ariidae e REIS (1986) verificou a grande importância dos bagres marinhos como segundo mais abundante grupo de peixes, contribuindo com $25 \%$ das capturas das pescarias artesanais.

Estudos de abundância relativa, distribuição e interações são de grande importância na ecologia de peixes. Dependendo de como duas espécies selecionam o mesmo habitat, pode-se detectar a existência de associação e/ou correlação entre pares de espécies, onde questões relacionadas à afinidade podem ser propostas (LUDWIG \& REYNOLDS 1988). Segundo ODUM (1988), espécies estreitamente aparentadas, isto é, com características morfológicas e fisiológicas semelhantes, apresentam com freqüência, similaridade quanto às necessidades de nicho, podendo ocorrer interações negativas quando os nichos são sobrepostos.

A coexistência em elevada abundância das espécies de Ariidae na Baía de Sepetiba pode ser devido ao desenvolvimento de estratégias de coexistência que permita a separação espacial ou temporal. O presente trabalho visa analisar os padrões espaciais e sazonais de distribuição, abundância relativa e interações entre estas espécies, fornecendo subsídios para o conhecimento da ecologia deste grupo de peixes.

\section{MATERIAL E MÉTODOS}

A Baía de Sepetiba localiza-se no Estado do Rio de Janeiro entre as latitudes $22^{\circ} 54^{\prime}$ e $23^{\circ} 04^{\prime} \mathrm{S}$ e as longitudes $43^{\circ} 34^{\prime} \mathrm{e} 44^{\circ} 10^{\prime} \mathrm{W}$ (Diretoria DE HidRografia E NAVEGAÇÃo 1984). Apresenta forma alongada, limitando-se a Norte e a Leste pelo continente, ao Sul pela Restinga de Marambaia e a Oeste por um cordão formado por diversas ilhas (Fig. 1). A partir desta formação de ilhas, definiu-se uma zona interna e uma zona externa, situadas fora da formação de ilhas, com maior influência das águas oceânicas. Por ser uma zona de poucos batimentos, o fundo da Baía é principalmente lodoso, com formações de silte, argila, na zona interna, e com poucas áreas de areia e cascalho, na zona externa. A profundidade máxima é de 30 metros, porém $40 \%$ de sua área apresenta profundidade média de 5 metros (COELHO \& CARVAlHo 1973). 


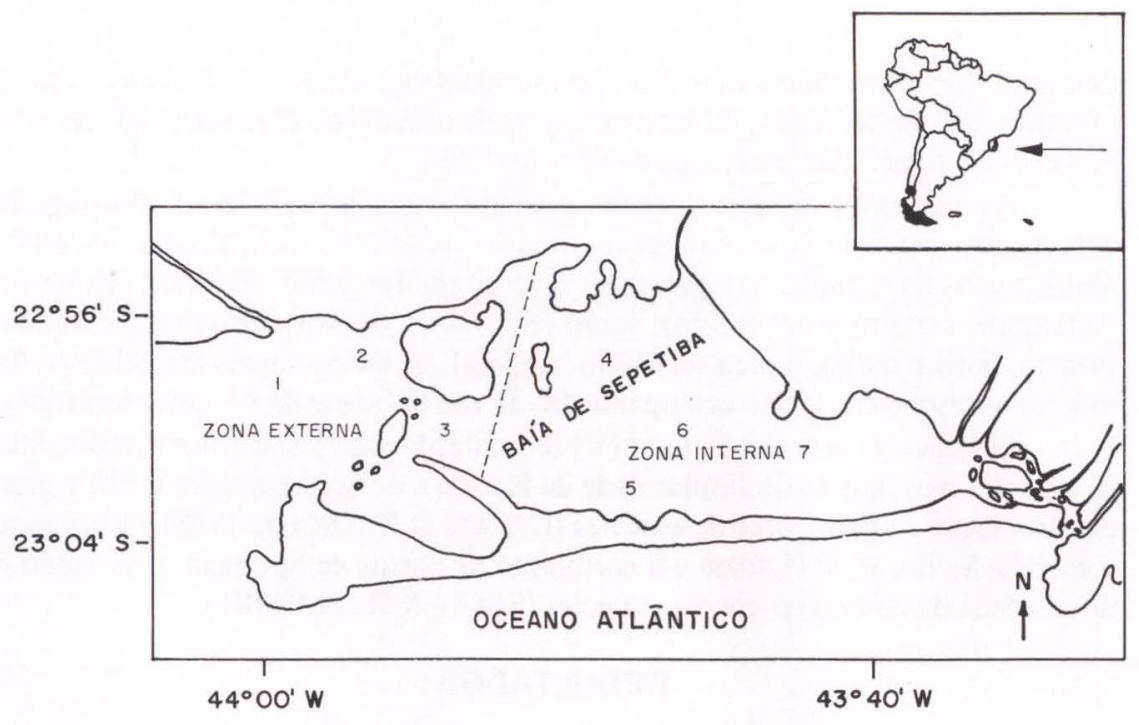

Fig. 1. Locais de coleta na Baía de Sepetiba, Rio de Janeiro. (1) Laje das Enxadas; (2) Ilha do Socó; (3) Ilha Bonita; (4) Costa do Guandu; (5) Canal da Restinga; (6) Meio da Baia; (7) Fundo da Baía. Adaptado de DiRetoria de Hidrografia e NAVEgaçÃo (1984).

Cento e cinqüenta e oito amostragens de arrasto de fundo foram realizadas em sete estações de coleta, entre julho de 1993 e junho de 1996. As amostragens foram mensais no período de julho de 1993 a julho de 1994 (primeiro ciclo anual), e bimestrais no período de julho de 1994 a junho de 1996 (segundo e terceiro ciclos anuais). Os arrasto de fundo foram realizados por arrasteiro com portas, utilizado na pesca comercial na Baía, apresentando $12 \mathrm{~m}$ de comprimento, provida de rede de arrasto de fundo com portas (otter trawl), com malha de $12 \mathrm{~mm}$ na região do saco e abertura de boca de $8 \mathrm{~m}$. Os arrastos tiveram duração padronizada de meia hora, velocidade de dois nós, cobrindo uma extensão de aproximadamente $1 \mathrm{Km}$. As estações de coleta foram definidas conforme sua localização na zona externa: 1) Laje das Enxadas; 2) Ilha do Socó; 3) Ilha Bonita; e interna: 4) Costa do Guandu; 5) Canal da Restinga; 6) Meio da Baía; e 7) Fundo da Baía.

Os peixes coletados foram separados por espécies, pesados, contados e medidos (comprimento total), sendo fixados em formol a $10 \%$ e posteriormente transferidos para álcool a $70 \%$. A identificação foi feita segundo FIGUEIREDO \& MENEZES (1978), tendo parte do material sido depositadas na coleção ictiológica do Laboratório de Ecologia de Peixes da Universidade Federal Rural do Rio de Janeiro.

A abundância relativa das espécies foi avaliada através do número de peixes por arrasto (CPUE) e peso dos peixes por arrasto (Biomassa). Análise de Variância foi realizada para comparar médias de abundâncias espaciais ou temporais. Os requisitos de normalidade e a homocedasticidade para esta análise foi obtida através da transformação logarítmica $\log (x+1)$, onde Log é o logaritmo na base 10 , e x é o valor (CPUE ou Biomassa) não transformado (SOKAL \& ROHLF 1981). Para a 
determinação das médias que são significantemente diferentes, toda vez que a hipótese nula for rejeitada, utilizou-se o teste de diferenças de médias de Tukey "a posteriori”, ao nível de confiança de $95 \%(\mathrm{p}<0,05)$.

As variações espaciais foram avaliadas considerando-se as estações de coleta. Para o critério de sazonalidade (estações do ano) considerou-se os meses de amostragens no seguinte agrupamento: inverno (junho, julho e agosto), primavera (setembro, outubro e novembro), verão (dezembro, janeiro e fevereiro) e outono (março, abril e maio), e para o critério temporal, os ciclos anuais amostrados. As médias apresentadas foram acompanhadas da variabilidade de $+/$ - um erro padrão.

$\mathrm{O}$ índice de associação total (V) foi utilizado para testar a associação entre as espécies e os índices de similaridade de Jaccard e de Sorensen para medir o grau de associação entre os pares de espécies (LUDWIG \& REYNOLDS 1988). Utilizou-se a correlação linear de Pearson e a correlação de postos de Sperman, para medir a intensidade da co-ocorrência das espécies (SOKAL \& ROHLF 1981).

\section{RESULTADOS}

\section{Abundância relativa, distribuição espacial e temporal}

Cinco espécies de Ariidae distribuídas em cinco gêneros foram identificados para a Baía de Sepetiba. A espécie B. marinus foi capturada somente em duas amostragens, e portanto, não foi incluída nas análises devido a sua baixa ocorrência.

Considerando os três ciclos anuais estudados, que começaram em julho-93 e terminaram em junho-96, variações na abundância relativa entre as quatro espécies foram verificadas. Nos ciclos de 1993/94 e 1994/95, G. genidens apresentou maior abundância relativa, seguida de C. spixii, S. luniscutis e N. barba. Em 1995/96, C. spixii apresentou maior abundância relativa, seguida de $S$. luniscutis, G. genidens e N. barba (Tab. I).

Tabela I. Abundância relativa em número e peso das espécies de Ariidae na Baía de Sepetiba, Rio de Janeiro.

\begin{tabular}{|c|c|c|c|c|c|c|}
\hline \multirow{2}{*}{ Espécies } & \multicolumn{2}{|c|}{ Ano 93/94 } & \multicolumn{2}{|c|}{ Ano 94/95 } & \multicolumn{2}{|c|}{ Ano 95/96 } \\
\hline & $\begin{array}{c}\text { Número } \\
(\%)\end{array}$ & $\begin{array}{c}\text { Biomassa } \\
(\%)\end{array}$ & $\begin{array}{c}\text { Número } \\
(\%)\end{array}$ & $\begin{array}{c}\text { Biomassa } \\
(\%)\end{array}$ & $\begin{array}{c}\text { Número } \\
(\%)\end{array}$ & $\begin{array}{c}\text { Biomassa } \\
(\%)\end{array}$ \\
\hline C. spixii & 22,1 & 32,6 & 17,1 & 15,3 & 80,8 & 61,9 \\
\hline G. genidens & 65,4 & 41,5 & 58,2 & 39,9 & 5,8 & 12,5 \\
\hline N. barba & 5,2 & 5,9 & 16,5 & 5,0 & 5,8 & 12,5 \\
\hline S. Iuniscutis & 7,3 & 20,0 & 8,2 & 40,2 & 13,4 & 25,5 \\
\hline
\end{tabular}

Em relação a biomassa, em 1993/94 G. genidens apresentou maior abundância relativa, seguida de C. spixii, S. luniscutis e N. barba. Em 1994/95, S. luniscutis e G. genidens foram as espécies com maiores abundâncias, seguidas de $C$. spixii e $N$. barba. No período de 1995/96, C. spixii apresentou maior biomassa, seguida de S. luniscutis, G. genidens e N. barba (Tab. I).

Cathorops spixii apresentou diferenças significativas $(\mathrm{p}<0,05)$ nas CPUEs e biomassas por estação de coleta, não apresentando diferenças significativas por 
estação do ano e por ano (Tab. II; Fig. 2). As estações de coleta da zona interna Costa do Guandu (Est. $4=233$ ind/arrasto) e Fundo da Baía (Est. $7=25,3$ ind/arrasto) apresentaram os maiores valores de CPUE sendo significantemente diferentes $(\mathrm{P}>0,05)$ em relação as estações da zona externa Laje das Enxadas (Est. $1=0,33 \mathrm{ind} /$ arrasto) e Ilha do Socó (Est. $2=0,09 \mathrm{ind} /$ arrasto). A biomassa foi também significantemente maior nestas mesmas estações de coleta, com Costa do Guandu (Est. 4) apresentando 2446,75 g/arrasto e Fundo da Baía (Est. $7=425,56$ g/arrasto), em relação as estações 1 (Laje das Enxadas $=28,57$ g/arrasto) e estação 2 (Illha do Socó $=2,38 \mathrm{~g} /$ arrasto) .

Tabela II. Análise de variância (ANOVA, $P<0,05)$ de número e peso de indivíduos $\left(\log _{10}(x+1)\right)$, de quatro espécies de bagres marinhos na Baia de Sepetiba, Rio de Janeiro. (EA) Estação do ano, (EC) estação de coleta.

\begin{tabular}{|c|c|c|c|c|c|c|c|c|c|}
\hline \multirow{2}{*}{ Espécies } & \multicolumn{3}{|c|}{ Ano 93/94 } & \multicolumn{3}{|c|}{ Ano $94 / 95$} & \multicolumn{3}{|c|}{ Ano 95/96 } \\
\hline & $E A$ & EC & $E A \times E C$ & EA & EC & $E A \times E C$ & $E A$ & EC & $E A \times E C$ \\
\hline \multicolumn{10}{|l|}{ Número } \\
\hline C. spixii & - & - & - & - & $6,7^{\star \star}$ & - & - & $4,6^{\star *}$ & - \\
\hline G. genidens & - & $7,5^{\star *}$ & - & - & $7,9^{* *}$ & - & - & $3,8^{\star *}$ & - \\
\hline N. barba & - & - & - & - & $5,1^{\star \star}$ & - & - & - & - \\
\hline S. luniscutis & $4,9^{* *}$ & $2,4^{*}$ & - & - & $4,4^{\star *}$ & - & - & $3,2^{*}$ & - \\
\hline \multicolumn{10}{|l|}{ Biomassa } \\
\hline C. spixii & - & $3,0^{\star \star}$ & - & $4,6^{*}$ & $4,8^{\star \star}$ & $3,0^{*}$ & - & $2,7^{*}$ & - \\
\hline G. genidens & - & $13,0^{\star *}$ & - & $5,1^{\star \star}$ & $3,5^{\star \star}$ & - & - & $3,8^{\star *}$ & - \\
\hline N. barba & - & $2,6^{\star}$ & - & $6,0^{\text {** }}$ & $6,6^{\star \star}$ & - & - & - & - \\
\hline S. Iuniscutis & $7,2^{\star \star}$ & $3,5^{\star \star}$ & - & - & - & - & - & $3,1^{*}$ & - \\
\hline
\end{tabular}

Genidens genidens apresentou diferenças significativas $(\mathrm{p}<0,05)$ nas CPUEs e biomassas por estação de coleta, não apresentando diferenças significativas por estação do ano e ano (Tab. II; Fig. 3). Observou-se interação entre estação do ano e ano de amostragem em relação a biomassa. As estações de coleta da zona interna Meio da Baía (Est. $6=128,4$ ind/arrasto), Costa do Guandu (Est. $4=104,12$ ind/arrasto), Fundo da Baía (Est. $7=72,8$ ind/arrasto) e Canal da Restinga (Est $5=$ 33,17 ind/arrasto) apresentaram significantes maiores CPUEs $(p<0,05)$ em relação as estações da zona externa Ilha Bonita (Est $3=1,0$ ind/arrasto), Ilha do Socó(Est. $2=0,38$ ind/arrasto) e Laje das Enxadas(Est. $1=0,14$ ind/arrasto). Quanto a biomassa, também as maiores diferenças significativas $(p<0,05)$ foram encontradas entre os maiores valores das estações da zona interna Meio da Baía (Est. $6=3515,21$ g/arrasto), Costa do Guandu (Est. $4=1512,83$ g/arrasto), Canal da Restinga (Est. 5 $=1313,60$ g/arrasto) e Fundo da Baía (Est. $7=1237,91$ g/arrasto) em relação as estações da zona externa de Ilha Bonita (Est. $3=189,13 \mathrm{~g} / \mathrm{arrasto}$ ), Ilha do Socó (Est. $2=101,19 \mathrm{~g} /$ arrasto) e Laje das Enxadas (Est. $1=26,66 \mathrm{~g} /$ arrasto).

Netuma barba apresentou diferenças significativas $(\mathrm{p}<0,05)$ nas CPUEs e biomassa por estação de coleta e por ano, não apresentando diferenças por estação do ano (Tab. II; Fig. 4). A estação de coleta Costa do Guandu (Est. $4=21,4$ ind/arrasto) apresentou maior CPUE $(\mathrm{p}<0,05)$ em relação as estações Canal da Restinga (Est. $5=2,9$ ind/arrasto), Laje das Enxadas (Est. $1=0,047$ ind/arrasto), 
$93 / 94$
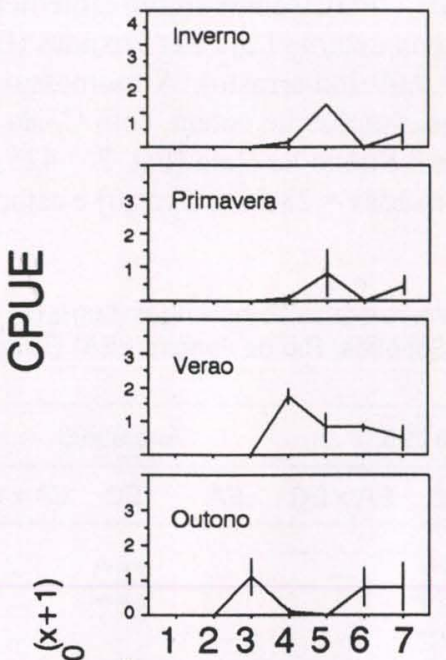

$\stackrel{8}{9}$

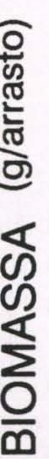

$94 / 95$
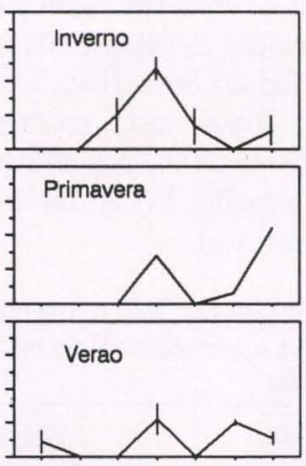

Outono

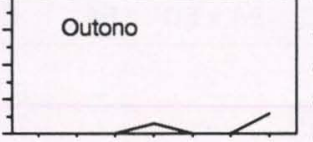

1234567
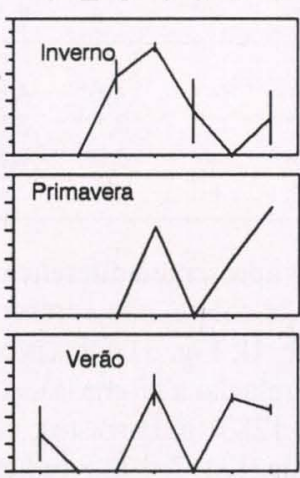

Outono
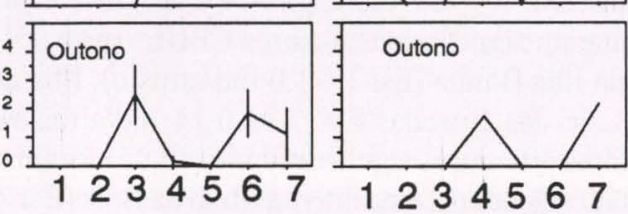

$95 / 96$
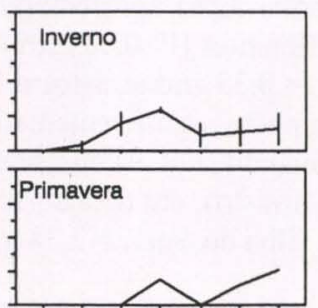

Verao

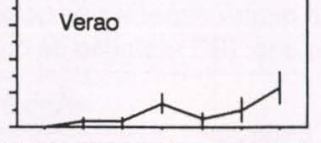

Outono
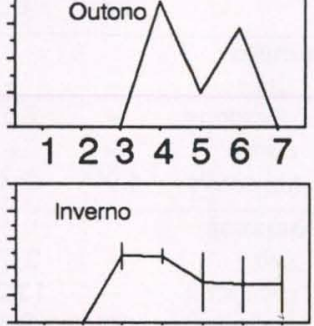

Primavera
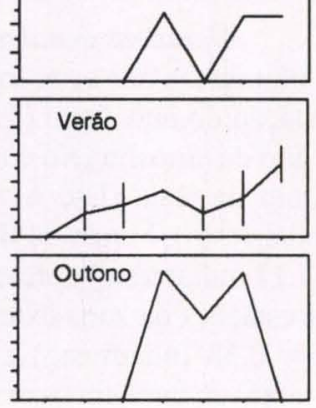

1234567

\section{Estações de Coleta}

Fig. 2. Distribuição espacial e temporal da CPUE e Biomassa com os dados transformados [ $\left.\log _{10}(x+1)\right]$ de C. spixii na Baía de Sepetiba, Rio de Janeiro.

Ilha do Socó (Est. $2=0.0$ ind/arrasto) e Ilha Bonita (Est. $3=0,0$ ind/arrasto). Quanto a biomassa, maiores valores foram encontradas na estação de coleta Costa do Guandu (Est. $4=686,25 \mathrm{~g} /$ arrasto) em relação as estações da zona externa Laje das Enxadas (Est. $1=1,19$ g/arrasto), Ilha do Socó $(0,0$ g/arrasto) e Ilha Bonita (0,0 
$93 / 94$
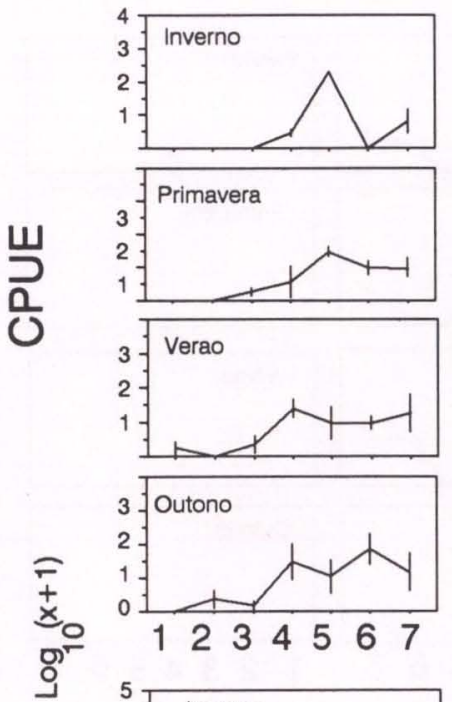

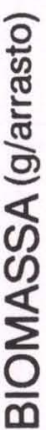
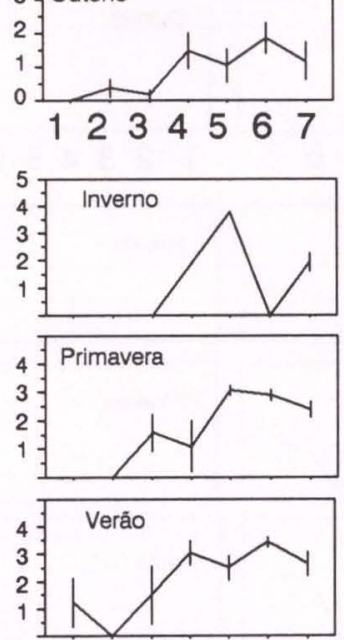

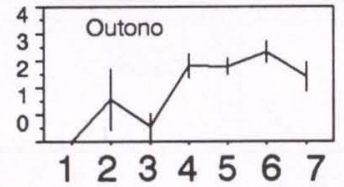

$94 / 95$
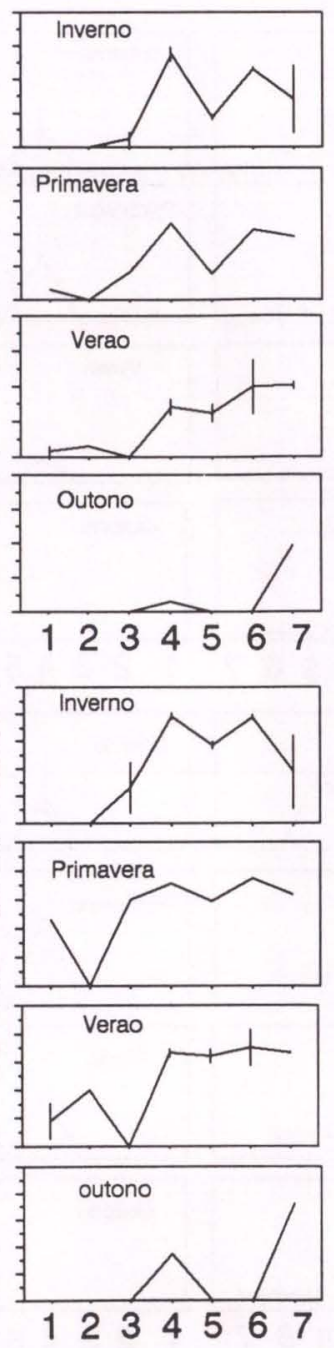

$95 / 96$
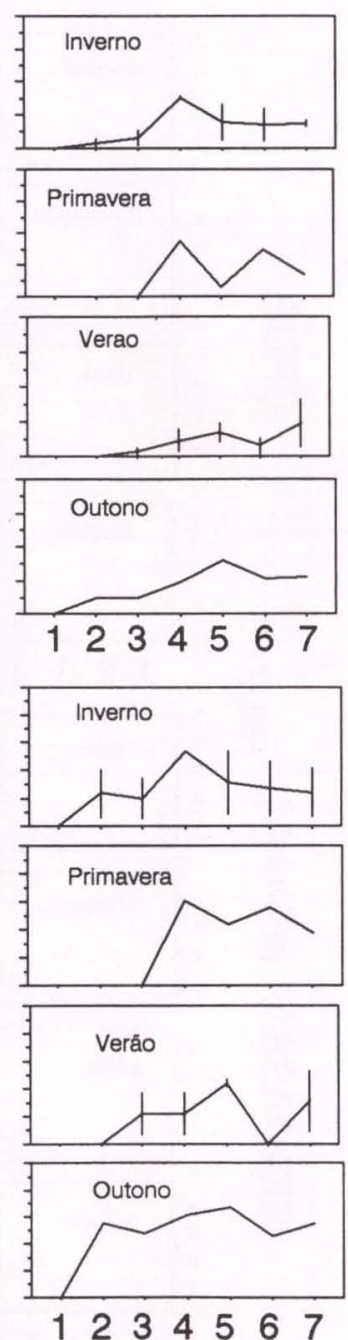

Estações de Coleta

Fig. 3. Distribuição espacial e temporal da CPUE e Biomassa com os dados transformados $\left[\log _{10}(x+1)\right]$ de G. genidens na Baía de Sepetiba, Rio de Janeiro.

$\mathrm{g} /$ arrasto). Esta espécie também apresentou maiores CPUEs $(\mathrm{p}<0,05)$ no ciclo anual 1994/95 (11,26 ind/arrasto) em relação a 1995/96 (0,11 ind/arrasto), e maiores biomassas no ciclo anual 1993/94 (245,73 g/arrasto) e 1994/95 (189,69 g/arrasto) em relação a 1995/96 (2,38 g/arrasto). 


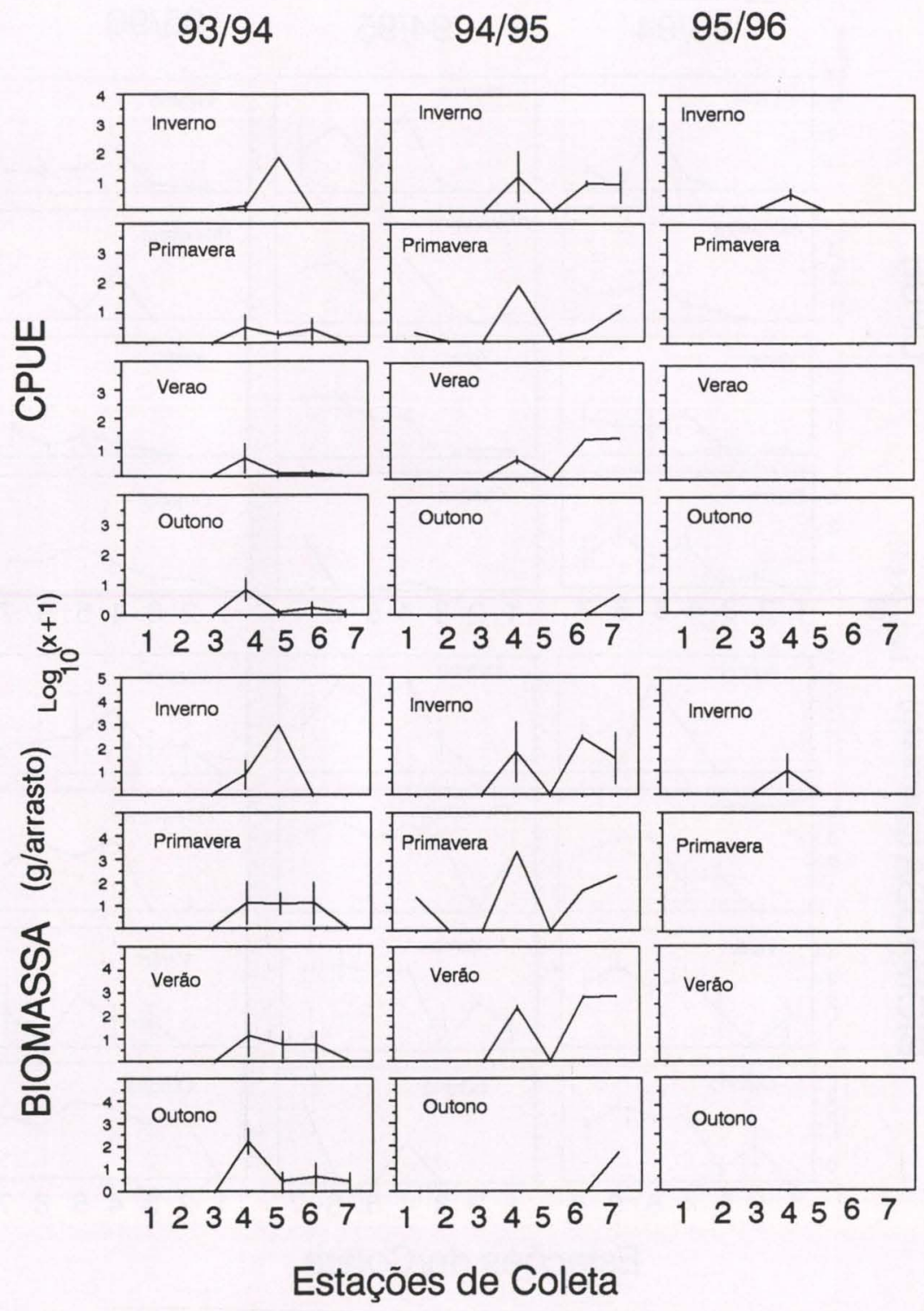

Fig. 4. Distribuição espacial e temporal da CPUE e Biomassa com os dados transformados $\left[\log _{10}(x+1)\right]$ de N. barba na Baía de Sepetiba, Rio de Janeiro.

Sciadeichthys luniscutis apresentou diferenças significativas $(\mathrm{p}<0,05)$ nas CPUEs por estação de coleta e por ano, não apresentando diferenças por estação do ano (Tab. II; Fig. 5). Observou-se interação entre estação do ano e ano de amostragem, e entre ano e estação de coleta (Tab. II). As estação de coleta da zona interna 


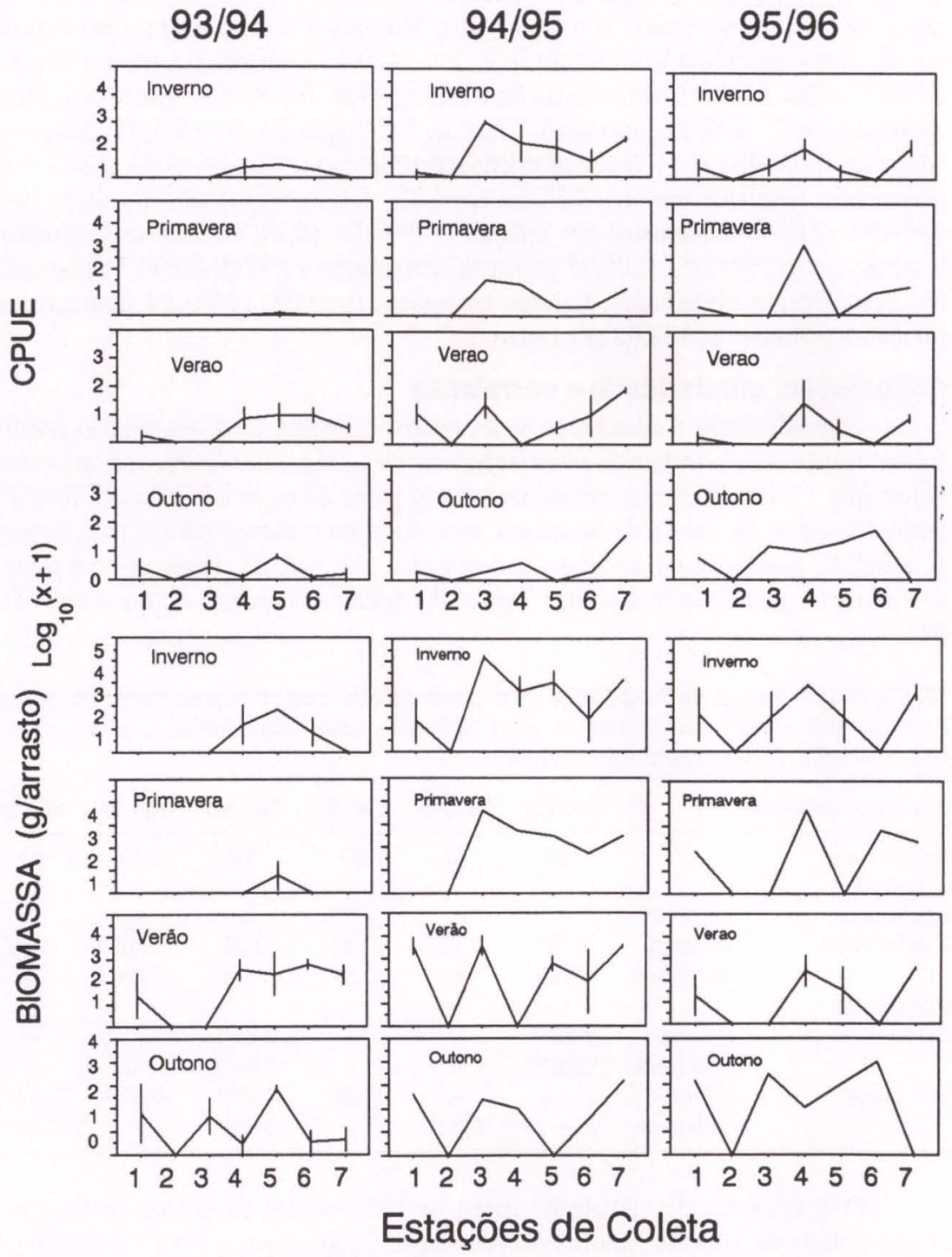

Fig. 5. Distribuição espacial e temporal da CPUE e Biomassa com os dados transformados $\left[\log _{10}(x+1)\right]$ de S. Iuniscutis na Baia de Sepetiba, Rio de Janeiro.

Canal do Guandu (Est. $4=42,7$ ind/arrasto), Fundo da Baía (Est. $7=15,21$ ind/arrasto) e Canal da Restinga (Est. $5=9,3$ ind/arrasto) apresentaram maiores CPUEs $(p<0,05)$ em relação a estação de coleta Ilha do Socó (Est. $2=0,0$ ind/arrasto). Em relação à biomassa, diferenças significativas $(\mathrm{p}<0,05)$ foram apre- 
sentadas por estação do ano, ano e estação de coleta, e interação entre estação do ano e ano de amostragem (Tab. II; Fig. 5). Maiores biomassas foram encontradas nas estações de coleta Ilha Bonita (Est. $3=2459,13$ g/arrasto), Laje das Enxadas (Est. $1=1082,14$ g/arrasto), Canal da Restinga (Est. $5=963,91 \mathrm{~g} /$ arrasto), Fundo da Baía (Est.7 = 858,21 g/arrasto), Canal da Restinga (Est. $5=963,91 \mathrm{~g} /$ arrasto) e Meio da Baía (Est. $6=786,3$ g/arrasto) em relação a Ilha do Socó (Est. $2=0,0$ g/arrasto). Também maiores CPUEs $(\mathrm{p}<0,05)$ foram registrados no ciclo anual 1994/95 (21,65 ind/arrasto) em relação a 1993/94 (6,24 ind/arrasto), e maiores biomassas em 1994/95 (1996,95 g/arrasto) em relação a 1993/94 (636,36 g/arrasto). No verão foram observadas maiores biomassas $(\mathrm{p}<0,05)(1463,04 \mathrm{~g} / \mathrm{arrasto}) \mathrm{em}$ relação a primavera (323,08 g/arrasto).

\section{Associação, similaridade e correlação}

Considerando a coexistência das quatro espécies, uma associação positiva foi apresentada pelo índice de associação total (V), cujo valor (2.003) se apresentou maior que 1. Nas diferentes combinações por pares de espécies, os coeficientes de similaridade de Jaccard e de Sorensen, apresentaram maiores valores para os pares C. spixii/G. genidens, G. genidens/S. luniscutis, e C. spixii/S. luniscutis em relação aos pares G. genidens/N. barba, C. spixii/N. barba e N. barba/S. luniscutis (Tab. III).

Tabela III. Indicadores de Associação entre pares de espécies de bagres marinhos (Ariidae) na Baía de Sepetiba, Rio de Janeiro. $(\mathrm{Cg})$ Cathorops spixii, $(\mathrm{Gg})$ Genidens genidens, $(\mathrm{Nb})$ Netuma barba, (SI) Sciadeichthys luniscutis.

\begin{tabular}{lccccccc}
\hline Pares de espécies & $\mathrm{Cs} / \mathrm{Cg}$ & $\mathrm{Cs} / \mathrm{Nb}$ & $\mathrm{Cs} / \mathrm{SI}$ & $\mathrm{Gg} / \mathrm{Nb}$ & $\mathrm{Gg} / \mathrm{SI}$ & $\mathrm{Nb} / \mathrm{SI}$ \\
\hline $\begin{array}{l}\text { Número de } \\
\text { amostras }\end{array}$ & & 109 & 76 & 97 & 98 & 119 & 91 \\
Associação & $(-$ ou +$)$ & + & + & + & + & + & + \\
Similaridade & Jaccard & 0,47 & 0,26 & 0,45 & 0,32 & 0,47 & 0,20 \\
Correlação & Sorensen & 0,64 & 0,41 & 0,62 & 0,49 & 0,64 & 0,34 \\
CPUE & Pearson & $0,30^{\star *}$ & - & - & $0,58^{\star *}$ & - & - \\
Biomassa & Sperman & $0,26^{* *}$ & - & - & $0,49^{* *}$ & - & - \\
& Pearson & - & - & $0,20^{*}$ & $0,27^{\star *}$ & $-0,17^{*}$ & $-0,34^{* *}$ \\
& Sperman & - & $-0,24^{*}$ & - & $0,34^{* *}$ & - & $-0,25^{\star *}$ \\
\hline
\end{tabular}

O coeficiente de correlação linear de Pearson e o de postos de Sperman, apresentaram os maiores valores de correlação positiva para o par de espécie $G$. genidens/N. barba em relação aos outros pares, tanto para as CPUEs como para as biomassas $(\mathrm{p}<0.01)$, seguido do par C. spixii/G. genidens, somente para CPUE. O par C. spixii/S. luniscutis, apresentou correlação positiva de Pearson $(\mathrm{p}<0,05)$, somente para biomassa (Tab. III).

Correlação negativa foi apresentada em relação à biomassa para o par $N$. barba/S. luniscutis, por ambos os coeficientes de correlação $(\mathrm{p}<0.01)$, para $G$. genidens/S. luniscutis pelo coeficiente de correlação de Pearson, e para o par $C$. spixii/N. barba, pelo coeficiente de postos de Sperman. 


\section{DISCUSSÃO}

Indicações de separação espacial entre as espécies de Ariidae são sugeridas a partir da análise dos resultados deste grupo de peixes da Baía de Sepetiba. Na zona interna da Baía de Sepetiba, onde os bagres marinhos são mais abundantes, $G$. genidens foi amplamente distribuído com picos de CPUEs e biomassas em todas as quatro estações de coleta, enquanto as demais espécies restringiram-se a uma ou duas estações. Todas as espécies estudadas, apresentaram consistentes ocorrências na estação 4 (Costa do Guandu), que localiza-se próxima a desembocadura do rio Guandu, o maior contribuinte de águas continentais da Baía. Esta ocorrência, pode dever-se a estratégias reprodutivas do ciclo biológico desta família, pois os bagres marinhos desovam em águas de baixa salinidade, procurando a desembocadura dos rios na época da desova (REIS 1982; YAÑEZ-ARACIBIA et al. 1976; LARA-DOMINGUEZ 1981).

Sciadeichthys luniscutis apresentou distribuição mais ampla em toda a Baía, com picos de biomassa, em todas as estações, tanto da zona interna como da zona externa, com exceção de Ilha do Socó (Est. 2), e de CPUE, somente na zona interna, onde verificou-se que indivíduos de maior tamanho ocorram na zona externa. Pode também ser sugerido que na zona interna da baía ocorram indivíduos adultos e jovens, indicando esta região como uma área de criação destes peixes. Esta situação não foi observada para as outras espécies, onde as maiores abundâncias em biomassa e CPUEs ocorrem na zona interna da baía. É importante acrescentar ainda, que maiores biomassa indicam espécie de maior tamanho em relação as demais.

Movimentos migratórios são citados para esta família. LARA-DOMINGUEZ et al. (1981) propõe um modelo do ciclo de vida de Arius melanopus na Lagoa de Térmitos, Golfo do México, onde esta espécie realiza movimentos sazonais no interior da Lagoa, completando seu ciclo neste ambiente costeiro. ARAÚJo (1988) observou que sub-adultos e adultos de $N$. barba no estuário da Lagoa dos Patos, Rio Grande do Sul, após a época da reprodução, migram para o mar, retornando no ano seguinte para a desova, sendo que os juvenis permaneceram dois anos no estuário. Segundo REIS (1982) N. barba migra do mar para a Lagoa dos Patos, para reproduzir-se em águas menos salinas do estuário.

Em geral, na Baía de Sepetiba, as espécies não apresentaram sazonalidade marcada. Somente em alguns anos, no entanto, algumas espécies demostraram tais variações. Genidens genidens no verão de 1994/95, apresentando maior abundância em biomassa que o outono. S. luniscutis, no verão de 1993/94, sendo mais abundante em biomassa do que a primavera.

Segundo LARA-DOMINGUEZ et al. (1981), a sazonalidade dos bagres marinhos, parece ser controlados por fatores como a temperatura e a salinidade. Estudos de ARAújo (1988) e ReIS (1982) no estuário da Lagoa dos Patos, e Mishima \& TANJI (1981) na região estuarina lagunar de Cananéia, sobre esta família em outra regiões demonstraram variações sazonais e espaciais. Estas regiões são definidas como estuários, apresentando condições de oligohalinidade e de instabilidade dos fatores ambientais. A Baía de Sepetiba, difere destes ambientes costeiros, pois apresenta maior estabilidade em relação aos fatores abióticos (SANTOS et al. 1997), podendo isto estar explicando a pequena sazonalidade nesta área. 
O uso compartilhado de um mesmo habitat por diferentes espécies tem sido abordado por LUDWIG \& REYNOLDS (1988) que sugerem questões relacionadas a interações entre as espécies, onde duas populações podem ou não afetar-se mutuamente.

Os pares de espécies C. spixii/G. genidens, G. genidens/S. luniscutis, e $C$. spixii/S. luniscutis apresentaram maior similaridade que $G$. genidens/N. barba, $C$. spixii/N. barba e $N$. barba/S. luniscutis. Estes índices são baseados na presença e ausência das espécies na amostra, sendo este resultado provavelmente devido a $N$. barba estar ausente na maioria das amostragens do período de 1995/96, o que levou as associações com $N$. barba apresentarem menor similaridade.

As biomassas parecem serem melhores indicadoras da correlação entre as espécies do que as CPUEs, pois através da inspeção dos gráficos de distribuição e abundância relativa, parecem refletir melhor a tendência geral de aumento ao longo do período estudado das espécies de $C$. spixii e $S$. luniscutis, em oposição à diminuição de $N$. barba e $G$. genidens. Os pares de espécies $G$. genidens/N. barba e C. spixii/S. luniscutis estão correlacionadas positivamente, isto é, as abundâncias das espécies aumentam ou diminuem juntas. Os pares de espécies $G$. genidens $/ S$. luniscutis, $N$. barba/S. luniscutis, e $C$. spixii/N. barba, estão correlacionados negativamente, isto é, quando a abundância de uma espécie aumenta, a abundância da outra diminui.

A modificação do padrão de abundância das espécies e a correlação negativa de $C$. spixii/S. luniscutis com $G$. genidens/N. barba, poderia sugerir uma competição, pois são espécies semelhantes e coexistem na mesma área. Segundo PIANKA (1982) a competição se produz quando duas ou mais espécies exploram os mesmos recursos e quando esses recursos são pouco abundantes. A interação entre duas populações reduz a eficácia biológica e/ou o tamanho das populações. Outra possibilidade seria as espécies terem diferentes tolerâncias a um determinado fator ambiental, o que poderia também causar a redução de uma população. Fatores ambientais como temperatura, salinidade e oxigênio dissolvido, transparência da água e profundidade, também podem estar relacionados à distribuição, abundância e movimentos dos bagres marinhos (ARAÚJO 1988).

Outros aspectos da biologia dos bagres marinhos, como os hábitos alimentares podem explicar a coexistência dos bagres marinhos. ARAúJo (1984) analisou hábitos alimentares de três espécies de bagres marinhos na Lagoa dos Patos, Rio Grande do Sul, onde a coexistência dos bagres no estuário não pareceu limitada pelo alimento, sendo suas dietas, em função da disponibilidade de alimento no estuário.

Portanto, estratégias de separação espacial, poderiam estar explicando a coexistência de bagres marinhos na Baía de Sepetiba-Rio de Janeiro, sendo, no entanto, necessárias maiores investigações sobre outros aspectos da bioecologia deste grupo de peixes que considerem os fatores abióticos e hábitos alimentares para uma melhor compreensão dos mecanismos de coexistência.

AGRADECIMENTOS. Aos estagiários do Laboratório de Ecologia de Peixes da UFRRJ, Iracema David Gomes e André Luiz Machado Pessanha, pela participação nas coletas, triagem das amostras e identificação das espécies. 


\section{REFERÊNCIAS BIBLIOGRÁFICAS}

ARAÚJO, F.G. 1984. Hábitos alimentares de três bagres marinhos(Ariidae) no estuário da Lagoa dos Patos, RS, Brasil. Atlântica 7: 47-63

Araújo, F.G.; A.G. Cruz-Filho; M.C.C. Azevedo \& A.C.A. Santos. 1998. Estrutura da comunidade de peixes demersais da Baía de Sepetiba, RJ. Rev. Brasil. Biol. 58 (3): 415-428.

1988. Abundância relativa, distribuição e movimentos sazonais de bagres marinhos (Siluriformes, Ariidae) no estuário do Lagoa dos Patos, RS. Revta bras. Zool. 5 (4): 509-543.

CRAIG, I.D.H. 1980. Contribution to the Knowledge of the Coastal Fish Species of the Peruibe Region. Part I: The Ariidae. Rev. Brasil. Biol. 40 (4): 755-758

Diretoria de Hidrografia e Navegação. 1984. Baía de Sepetiba. Rio de Janeiro, Carta Naútica No. 1621.

Figueiredo, J.L. \& N.A. MENEZES. 1978. Manual de peixes marinhos do Sudeste do Brasil. II Teleostei (1). São Paulo, Universidade de São Paulo, Museu de Zoologia, 110p.

LARA-DomingueZ, A.L.; A. YAÑEZ-ARACIBIA \& F.A. LinHARES. 1981. Biologia e ecologia del bagre Arius melanopus Gunther en Laguna dos Térmitos, sur del Golfo do México (Pisces: Ariidae). An. Centro Ciências Mar Limnol., México, 8 (1): 267-304.

LUDWIG, J.A. \& REYNOLDS. 1988. Statistical Ecology: A primer on methods and computing. New York, Wiley-Interscience Publications, 337p.

MishimA, D. \& S. TANJI. 1981. Distribuição geográfica dos bagres marinhos (Osteichthyes, Ariidae) no complexo estuarino lagunar de Cananéia $\left(25^{\circ} \mathrm{S}\right.$, $48^{\circ}$ W). Bol. Inst. Pesca, São Paulo, 8: 157-172.

ODUM, E.P. 1988. Fundamentos de Ecologia. Lisboa, Fundação Calouste Gulbenkian, $4^{\mathrm{a}}$ ed., 927p.

PIANKA, E.R. 1982. Ecologia evolutiva. Barcelona, Ediciones Omega S.A., 365p. REIS, E.G. 1982. Age and growth of the marine catfish, Netuma barba (Siluriformes, Ariidae), in the Estuary of the Patos Lagoon (Brazil). Fishery Bulletin 84 (3): 679-686.

REIS, E.G. 1986. A pesca artesanal de bagres marinhos (Siluriformes, Ariidae) no Estuário da Lagoa dos Patos (RS), FURG, Documentos Técnicos, Rio Grande, $5,22 \mathrm{p}$.

Santos, A.C.A; F.G. Araújo; A.G. Cruz-Filho \& M.C.C. Azevedo. 1997. Distribuição e abundância relativa de Gerreidae (Osteichthyes, Perciformes) na Baía de Sepetiba, RJ. Arq. Biol. Tecnol. 4 (3): 672-686.

SOKAL, R.P.\& F.J. ROHLF. 1981. Biometry: the principles and pratice of statistcs in biological research. San Francisco, W.H. Freman and Co., $2^{\text {nd }}$ ed., 776p.

YAÑEZ-ARACIBIA, A.; J. CURIEL-GomeZ \& V.L. YAÑEZ. 1976. Prospeccion biológica y ecológica del bagre marino Galeichthys cearulensis (Guntter) en el sistema lagunar costero Guerrero, México (Pisces: Ariidae). An. Centro Ciências Mar Limnol., México, 3 (1): 125-180.

Recebido em 04.VII.1997; aceito em 26.X.1998.

Revta bras. Zool. 15 (4): 853 - 865, 1998 